\title{
Visual Manifestations of the European Discourse on Solidarity of Refugees and Migrants
}

\author{
Efharis Mascha \\ Hellenic Open University, Patras, Greece
}

\begin{abstract}
The paper aims to examine different visual manifestations of the European discourse on solidarity during the immigration crisis (2015-2017). International Organizations such as UN (United Nations), IOM (International Organization for Migration), and EASO (European Asylum Support Office) following a set of European policies reflect solidarity in practice among the European Union (EU) states. Policy makers, apart from implementing and drafting different sets of policies in moments of emergency due to the immense migrant flow, have also accompanied these practices with visual representations in the form of posters and photos. These visual representations feature the organizations themselves and the discourse on solidarity towards the migrants. Hence, examining this material we can have a clear picture of the identity of the organizations but also, and most importantly, how they visualize their understanding of solidarity discourse. The paper is unfolded in the following way. Firstly, the theoretical framework of solidarity and the European Union's perspective of solidarity are discussed in detail. Then, the focus is moved towards a theoretical discussion of emotion, the role of affect, and the role these Organizations play in the creation of European policies on migration. Thirdly, the analysis of the material, photos, posters, and a leaflet will be discussed in conjunction to the aforementioned theoretical framework of solidarity and affect.
\end{abstract}

Keywords: solidarity, emotion, affect, refugee policy, Greek Asylum Service

\section{Introduction}

The paper was inspired by the museum exhibition A World of Emotions: Ancient Greece 700 BC-200 AD which was initially presented at the Onassis Cultural Center in New York in March 2017 and was later exhibited in the Acropolis museum in autumn 2017. Both, Dimitrios Pandermalis, President of Acropolis museum and Dr. Antonis Papadimitriou, President of the Onassis Foundation, agree on the fact that "emotions were present everywhere in the culture and lives of the ancient Greeks and that they also have a special place in understanding ancient Greek art, literature, history, political life, society and religion" ("Exhibition Brochure", 2017, p. 4) and that the exhibition's mission is "to help us empathize with the ancient world and the emotions that ruled it" ("Exhibition Brochure", 2017, p. 5). So, emotions and empathy as a vehicle to understand culture were central at the particular museum exhibition.

The paper aims to address the issue of visual manifestations of refugees and migrants and the role of affect in the analysis of the aforementioned representations as a methodological approach to the European discourse of solidarity. So far there has been a vast array of research and published articles with regards to solidarity, policy making, refugee law, human rights, and international relations, but there is limited work dedicated to

Efharis Mascha, Ph.D., Adjunct Lecturer, Hellenic Open University, Patras, Greece. Email: mascha.efcharis@ac.eap.gr 
what is by prima facie said and felt, and that is, the role of affect in refugee policy.

Firstly, the paper discusses the role of solidarity in the European discourse, and then moves to a theoretical encounter on emotion. Emotions are seen as the link between the individual and the social. Emotions cover a vast array of human expressions from happiness to grief and sorrow. They are discussed not from an individualistic, personal perspective but from a social-cultural one. Having this background knowledge, we will move forward to a thorough investigation of the role of affect in politics. Our claim is that affect plays a significant role in the construction of a political discourse about refugees and migrants. Moreover, it is affect that can lead us to cultural empathy and enhance policy making with values such as solidarity, understanding, openness, and integration.

Secondly, a twofold empirical analysis is displayed. On the one hand, a set of photos and a published leaflet will be presented and analyzed in conjunction with the role of affect in discourse theory. The analysis will be assisted by a set of interviews, which were conducted with the head of public relations of the Greek Asylum Service, Eleni Petraki, the photographer, Andrea Bonetti, and the graphic designer, Christina Tsevis.

\section{Solidarity as Concept and Discursive Construction}

\section{Solidarity in Theory}

Solidarity is used in a vague and undetermined sense, somehow hidden within the political rhetoric of actors, political parties, and/or institutions such as European Union (EU) members and institutions (Kontochristou \& Mascha, 2014, p. 51). Theoretically speaking, the notion of solidarity could be addressed and conceptualized by drawing on Quentin Skinner. According to Skinner (1980), solidarity requires a threefold study. First, the society within which this idea is formulated. Second, the term itself, which refers to the use of the different equivalents of the same word (e.g., brotherhood, fraternity, unity). The third is the context, which can be divided into the conceptual context, the political context, and the historical or structural context. The conceptual context refers to the relationship between the concept in question and other concepts; the political context refers to the relationship between political parties and alternative strategies whereas the historical/structural context refers to the economic boundaries nationally or internationally (Stjernø, 2005).

Similarly, and more importantly, a post-structural discourse theory understands solidarity and the dominant metaphors of solidarity. Therefore, as Honohan (2005, p. 2 in Stjern $\varnothing$, 2005) suggests, we could understand solidarity either as a membership of bounded entity or from the spectrum of social capital. In both cases the basic principle that prevails is that the discursive construction of solidarity emphasizes the relationships among individuals and groups and problematizes the wholeness of solidarity within specific boundaries (family, nation, ethnicity, culture).

If we problematize social boundaries, then solidarity brings to the fore an important sociological issue: inclusion versus exclusion. Classic social theorists such as Emile Durkheim and Georg Simmel considered solidarity to be the constitutive element that made society possible in the first place (Durkheim, 1893; Simmel, 1908; Wilde, 2007 in Stjernø, 2005). While Durkheim distinguished between mechanical and organic types of solidarity ${ }^{1}$, Simmel noted the role of religion as the binding factor for social order. Marx himself and the

\footnotetext{
${ }^{1}$ In Emile Durkheim's Division of Labor in Society (1893), "mechanical solidarity" characterizes primitive societies. The members of that society are more likely to resemble each other and share the same beliefs and morals. Solidarity becomes more organic as these societies develop their divisions of labor. In particular, "organic solidarity" is understood as a natural outcome resulting from social interactions generated by the division of labor in modern societies.
} 
Marxist tradition understood solidarity in the form of class solidarity. This was later developed further and both in terms of structure and ideology, the use of solidarity within the Marxist arena was discussed exclusively as the solidarity of the working class (Kautsky (1915), Gramsci (1971), and Lenin (1902) in Stjernø, 2005) .

However, the exploration of the use of solidarity within the recent European political spectrum is crucial. Solidarity as a concept has historically changed ${ }^{2}$ and focused on broadening democratic participation. The Social Democrat solidarity concept poses the issue of individualism versus collective action (Freeden, 1996, p. 443). Since the late 1980s, many Social Democrat political programs tried to reconcile the freedom of the individual to pursue his or her interests and the needs of the community. The Christian Democrat agenda emphasizes subsidiarity and personal responsibility and confers a weaker role upon solidarity (Stjernø, 2005, 240ff). However, there is a sector within Christian Democrat discourse that pays particular attention to solidarity issues (i.e., Social Christians). In other words, both parts of the European discourse on solidarity face the issue of individualism versus collective action but from different perspectives.

Generally speaking, the issue of individualism is raised due to the increased level of social mobility, the change in education to more individualist patterns, and the acute concerns with the specialization of science, which consequently has led to increased specialization in the work arena as well (Kontochristou \& Mascha, 2014, p. 51). Furthermore, due to the debt crisis within the Eurozone and the contested practices of the welfare state, the Mediterranean countries are faced with distrust from the Centre-North EU countries. Hence, a discursive analysis of solidarity would enable as to see clearly that solidarity is an unbounded entity and there are certain salient relationships/policies among the EU states, which clearly detest the basic solidarity principle.

\section{European Solidarity "Faces"}

So, the question remains what solidarity means in the European context, if it's a question of self-interest or community, and whether democracy and sovereignty during the migration crisis were put into question. Moreover, if there is a moral imperative in terms of reciprocity among inter-state policies, then how is the responsibility and coordination of the huge immigration wave shared among states? Although solidarity was one of the constitutional principles ${ }^{3}$ of the creation of the European Union, it's unclear the legal, political, economic, and moral limits of European solidarity. And in particular, in the context of migration policy how much solidarity has been exercised thus far? Sofia Fernandes and Eulalia Rubio (2012, p. 4) in their study for the think tank Notre Europe argue that European solidarity in the EU is organic solidarity, that is, functional than emotional. More specifically, they maintain that a distinction can be made between two different rationales inspiring inter-state solidarity in the EU, namely, direct reciprocity (I help others so that they will help me in the future in case of need) and enlightened self-interest (I help others because I know that acting in the interest of other EU members or in the interest of the EU as a whole ultimately serves my own self-interest) (Kontochristou \& Mascha, 2014, p. 52). The direct reciprocity solidarity logic in the EU underpins the classic insurance-type schemes: for example, the EU Solidarity Fund, which comes to the aid of any member state affected by a natural disaster, or the Lisbon Treaty's "solidarity clause" according to which member states "shall act jointly in a spirit of solidarity if a member state is the object of a terrorist attack or the victim of a

\footnotetext{
${ }^{2}$ Stjernø $(2005,93 \mathrm{ff})$ suggests three possible explanations for the historical change in the use of solidarity. First, it is a change in the class structure and the need for electoral alliances. Second is the cultural change after 1968 that rendered the need for social democracy to broaden the concept of solidarity acute, and third is the nature of political symbols and programs.

3 "Europe will not be made all at once, or according to a single plan. It will be built through concrete achievements which first create a de facto solidarity" (Robert Schuman, The Schuman Declaration, May 9, 1950).
} 
natural or man-made disaster" ${ }^{4}$ (Fernandes \& Rubio, 2012, 4f). The ultimate purpose of this solidarity arrangement is to provide reciprocal aid in face of a risk that is evenly spread across all the EU member states. All EU countries then are potential givers and receivers of help and today's provider of help can be tomorrow's beneficiary (ibid.). However, solidarity is not a one-way approach but has to include commitments of responsibility. As noted by Jérôme Vignon (2011), any solidarity act has a counter-part element of responsibility from the country receiving the aid, and solidarity only grows stronger with consequent responsibility. Moreover, the exercise of inter-state solidarity in the EU concerns coordination. Coordination can serve to diagnose, prevent and redress divergences within a group and can help reduce risks such as the current debt crisis (Kontochristou \& Mascha, 2014, p. 52).

Solidarity and coordination were debated in two contrasting visions: Germany and France. The French position was reflected in Art $103 \mathrm{TEU}$, which stated that member states should regard their economic policies "as a matter of common concern", whereas the German position was mainly reflected on the introduction of a "no bail-out" clause (Art 104b TEU), which actually forbids the European Union from helping an Economic and Monetary Union country that fails to meet its financial obligations. The latter seems to contradict, to some extent, the vision of Europe envisaged in the TEU and the Lisbon Treaty, where the European Union "shall promote economic, social and territorial cohesion, and solidarity among Member States" (Kontochristou \& Mascha, 2014, p. 52).

At this point, it's worth mentioning a set of policies, which were built by the EU in order to deal with the massive wave of migrants and refugees residing the Mediterranean coasts mainly of Greece and Italy during 2015. More specifically, the Dublin Convention, entails family reunification and the relocation scheme. I have previously presented a detail analysis on these policies and pointed out dislocatory elements of the European solidarity (Mascha in Martilla, 2018, pp. 209-216).

Having seen this theoretical encounter on solidarity, we will now move forward to the discussion of emotions and affect from a discourse theoretical perspective so as to build the necessary methodological framework for the analysis of the empirical material. Our aim is to see how emotions and affect play a significant role in the discourse of solidarity

\section{Theoretical Encounter on Emotions}

Emotions had been considered to be infantile and uncivilized, hence need to be controlled so as society to work properly and rationally (Planalp, 1999 in Pribram \& Harding, 2004). In a sense emotions were believed to be destructive and non productive for social order. However, social sciences and humanities have recently showed a great interest in the study of emotions as sociocultural products and a more in depth analysis can actually reveal emotions as products of power relations. Therefore, we will discuss this theoretical standpoint based on Raymond Williams' concept "structure of feeling” and Lawrence Grossberg's concept "economy of affect”.

How Raymond Williams considers "structure of feeling"? For Williams "the structure of feeling is the culture of a period: it is the particular living result of all the elements in the general organization" (Williams in

\footnotetext{
4 "The Union shall mobilize all the instruments at its disposal, including the military resources made available by the Member States, in order to: prevent the terrorist threat in the territory of the Member States; to protect democratic institutions and the civilian population from any terrorist attack; assist a Member State in its territory, at the request of its political authorities, in the event of a terrorist attack" [Art 222 1(a) TFEU]; "to assist a Member State in its territory, at the request of its political authorities, in the event of a natural or man-made disaster" [Art 222 1(b) TFEU].
} 
Harding \& Pribram, 2009, p. 36). As Pribram and Harding (2004) put it, structure of feeling "is an attempt to formulate the place of emotions in culture". In order for Williams to provide an operative account of the concept "structure of feeling" he studied in detail English literature during the 17th and 18th century and he reached a set of conclusions with regards to the role of emotion as "structure of feeling" which are useful and significant.

Firstly, and most important, he considers the structure of feeling unique to every culture through time and place and non-transferrable from generation to generation. In his own words, one generation may train its successor, with reasonable success, in the social character or the general cultural pattern, but the new generation will have its own structure of feeling, which will not appear to have come "from" anywhere (Williams in Harding \& Pribram, 2009, p. 36).

Secondly, Williams uses structure of feeling as a "class-linked concept, analyzing what he believes are the principle structures of feeling for each class in a particular era" (Pribram \& Harding, 2004, p. 4). Hence, traces of the structure of feeling can be linked to the dominant class and as it is very difficult to revive the structure of feeling of a past society we need to dig deeply in its tradition, documentary, and literature.

Thirdly, Williams links structure of feeling with "experience" (Williams in Pribram \& Harding 2004, p. 6). In what sense? Firstly, because experience represents an authentic expression of feeling and for Williams, it is very difficult if not impossible to capture this feeling, when talking about societies in the past. And secondly, experience for Williams is real and immediate and thus credible.

Having these dimensions in mind Pribram and Harding (2004) moved a step forward and chose to emphasize, and I definitely agree on this, the productive process that jumps out from the analysis of structure of feeling in every social order. More specifically, following Pribram and Harding "in the notion of structure of feeling, the emotions are culturally constituted and culturally shared [...] with structures of feeling, the emotions become a widely held cultural experience, not solely an individual (biological or behaviorist) one" (2004, p. 8). As mentioned earlier on, Williams didn't seem to link structure of feeling with power relations and thus, following Pribram and Harding (2004), it is imperative to see Lawrence Grossberg's account of "economy of affect" in order to have a fuller theoretical encounter on emotion.

Grossberg's work mainly explores how power operates through affect. At the same time, influenced by Foucault, he believes that power is subsumed in meaning and that "meaning must be located as a function or effect of power" (Grossberg in Pribram \& Harding, 2004, p. 8). He is highly critical of the postmodernist both of the positive and negative account of affect as pleasure and argues that they tend to ignore the complex relations of power that exist between pleasure and ideological formations. Also, they ignore or there is a lack of understanding between pleasure and form of resistance. In a sense, following Grossberg we need to describe pleasure and then return to the question of political articulation (Grossberg in Harding \& Pribram, 2009, p. 76). So, let us map out what is "economy of affect" for Grossberg.

Similarly to Williams, Grossberg links "the individual with the social formation through the activities and energies of affect" (Grossberg in Pribram \& Harding, 2004, p. 10). For Grossberg affect is a constitutive part of popular culture and he differentiates it from emotion. Specifically, he states that "emotion exists when affect is mediated with ideology, and specific emotions exist when specific combinations of affect and ideology merge or clash" (Grossberg in Pribram \& Harding, 2004, p. 11). So, for Grossberg affect is a energy and an investment, constitutive to popular culture. 
To sum up, having this theoretical discussion in mind, we will move towards a better understanding of what is known as affect from a discourse theoretical point of view.

\section{The Transition From Emotion to Affect in Discourse Theory}

Why affect is not simply emotion? The answer is simply because of fantasy. Discourse theory has been systematically engaged in psychoanalytic terms and affect is one of its Freudian categories, which will be discussed here in further detail. First of all, we need to clarify that Freud's ideas about affect have had an important place in analytic work. He went on to explain how idea and affect follow separate paths. Whilst ideas remain at the level of consciousness, affect corresponds to the process of discharge. Lacan, on the other hand, dismissed the Freudian notions of idea and affect (Benvenuto \& Kennedy, 1986, p. 168). Hence, for Lacan, the reference should be made to jouissance and not to affect. Therefore, if we need to examine the notion of affect, we need to put it within the psychoanalytic spectre of the Symbolic - the imaginary and the real and we need to tackle the issue of fantasy.

But let's begin with the notion of fantasy. Having in mind Laclau and Mouffe's thesis that "Society doesn't exist", we then follow Zizek who explicitly asserts that "Society as a corporate Body is the fundamental ideological fantasy" (Zizek, 1989, p. 126). And he explains further, "fantasy is a means of an ideology to take its own failure into account in advance". In other words, fantasy is the domain where all possible antagonisms or antagonistic relationships take place. Moreover, there is a whole network of symbolic overdeterminations that suffice in the realm of fantasy. Fantasy is "what links the subject affectively to socio-political reality" (Ruitenberg, 2010, p. 50). As Stavrakakis (2012) mentions, fantasy and identity formation is based on the promise of a lost jouissance signified as a total fullness. However, this total fullness entails an imaginary fullness or wholeness (beatific side of fantasy) and a disaster (horrific side of fantasy) (Glynos, 2011, p. 376). The latter is similar to the "theft of enjoyment" (Glynos \& Mondon, 2016, p. 7). Hence, when studying fantasy and the role of affect, the important part of identity formation is whether it is constructed positively around emotions of enjoyment or it is formulated as a loss of enjoyment. Similarly as Marttila (2015, p. 88) has pointed out, affective attachments cannot explain any particular social outcome such as the presence of a particular set of positive identities. Therefore, identity formation is not caused by affect but during the process of identification there is a certain affective attachment.

So, in a sense our discussion about affect goes through the notion of fantasy and the process of identification where affect plays a particular role. In practical terms, affect is a sticky substance in the realm of fantasy, which in Lacanian terms works as a promise to fulfill the absent fullness of the real. As very well stated by Glynos and Stavrakakis (2008, p. 9), "fantasy links the 'dry' socio-symbolic field (through a reference to its official insignia) to the 'sticky' affects of the subject". And they go on to point out that "a key aspect of understanding the significance of emotions in the organization of social practices involves trying to map them in relation to the underlying fantasies which organize a subject's affective enjoyment" (2008, p. 12). During the empirical analysis of the specific visual manifestations of refugees and migrants, we wish to point out this spectre of fantasy — enjoyment — lost fullness and their affective attachments, which are linked to the discourse of solidarity.

\section{Empirical Study}

Following a theoretical framework on solidarity, the EU faces of solidarity and an understanding of 
emotions as constitutive parts of culture together with an approach of affect in discourse theory we will now present two projects released from the Greek Asylum Service. The first one refers to a project initiated by the Greek Asylum Service and the financial support of EASO (European Asylum Support Office), so as to decorate pictures and banners from refugees and migrants homogeneously to the headquarters of the Asylum Service in Athens and the 14 Regional Offices. The second one refers to a leaflet made for unaccompanied minors and is funded by the EU and the Asylum Service.

\section{The Research Outcomes}

The first project, the photos were meant to become posters and decorate the main building of the Asylum Service and the Regional Offices. The aim was the Asylum Service to have a homogeneous picture in all premises and to be closer to the images and lives of the asylum applicants. The project was funded by EASO and the pictures were donated by Andrea Bonetti. Due to the limits of the particular work, I selected few pictures to present here. Pictures refer mostly to the travel, the family reunification, and the relocation program.

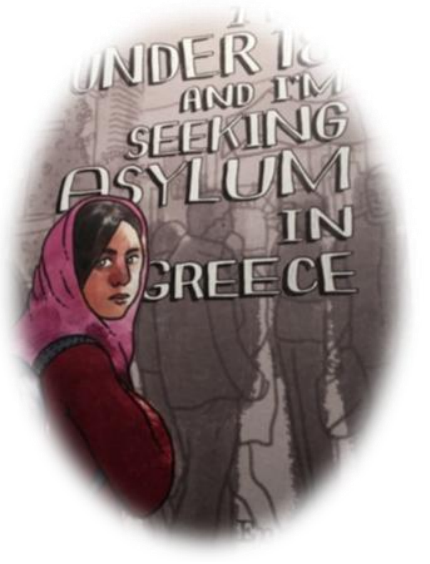

Figure 1. Leaflet of Greek Asylum Service by C.Tsevis.

I had the chance to discuss the whole project with the head of public relations of the Greek Asylum Service, Eleni Petraki, who was clearly dissatisfied with EASO's support to the specific project. She actually told me that they had placed the order for printing to EASO twice, but they did a lot of cropping in the pictures while printing and instead of placing the photos in a nice frame, they simply posted them in paper form. Hence, the project hasn't finished yet and only some posters and banners are put in place throughout the main building of the Greek Asylum Service. Talking with the photographer, Andrea Bonetti, who actually donated his pictures to the Asylum Service, he also mentioned this mishap with EASO's printing and the cropping as well. He also talked about the pictures and the moment he took them, mainly in Moria-Lesvos in November 2015 and some of them featuring the first day, the relocation program was launched in 2015 . He mentioned that he tried to capture a very harsh moment of people's lives, their experience, and the moment they get out of the boat is really difficult, actually tragic. As Williams (2004) noticed, experience entails emotion. Bonetti chose black and white so as to show this difficulty. Most of them were happy and thrilled that they were safe, some were crying, and others did not want their picture to be taken. He also mentioned that he wanted to show the tragic moment they lived during their travel. The second project I had the chance to discuss with Eleni Petraki was a much more successful project and well delivered in all Non Governmental Organizations with regards to unaccompanied minors and their rights as asylum applicants. This project was launched on the 26 January 2017; 
it is teens friendly, pocket size leaflet and written in six different languages (English, French, Farsi, Dari, Urdu, and Bengali). The pictures are all real ones and instead of using typewriting, handwriting was used to all leaflets. Petraki was proud and happy about this project, showed clearly her sensitivity about minors and the need to convey to them in a teens friendly leaflet their rights and duties. She pointed out "the Asylum service girl" and the "boat". Talking with the graphic designer, Christina Tsevis, about the particular project, received the same feelings of pride and satisfaction about the project and especially collaborating both with Petraki and Stavropoulou, the former director of the Asylum Service. She mentioned that she was free to choose the pictures and do all the graphic designing. She also pointed out that she wanted to show clearly the difference of the unaccompanied minors, who are different, who feel alone and strangers. She focused on positive emotions and she drew pictures from real people and places within the Asylum Service so as for the minor who reads the leaflet to feel safe and at home with the place. She also talked about the girl inside the boat (Figure 3), who seems to be dreaming about her future. She said: "I didn't want any child to have an unease look" but also "not to look very happy". She aimed to neutrality and to realism. She explained that the situation is really bad and dull but the emotions minors have are powerful and intense. She wanted to do a project that any unaccompanied minor could identify himself/herself with the ones in the drawings.

The Travel. Nothing could capture better the fantasy of the travel than the Mexican dram film directed by Spanish-born Mexican director Diego Quemada-Díez, The Golden Dream (Spanish: La jaula de oro; literally: "The Cage of Gold") $)^{5}$. The travel is a golden dream for most immigrants and refugees either they are meant to escape from any type of persecution or maltreatment or they want to escape from poverty and make a new beginning. The promise of a "golden land" where welfare state policies are implemented, integration program are in hand and people wait for them full of emotions of solidarity, openness and understanding is the promise of a lost fullness, thus fantasy. The affective investments of this fantasy makes the travel possible and jouissance present, because it is generally full of misfortunes, military push backs, hunger, sexual exploitation, drowning, and theft. The following two pictures, Figure 2, Bonetti captured in Moria and Figure 3 Tsevis presented in the leaflet, represent this promise, the travel through a horrific to a beatific land, where a new beginning is awaiting. Moreover, Chevis's little boat, named hope on Figure 4, affectively invests this promise. Hope is an emotion and an idea; it's an empty signifier that can keep the dream open and possible; hope of a different world, a peaceful world, a world more colorful than the grey life of war and the grey colors of travelling in between mines, military push backs and smugglers. During this travel, minors become adults even if the journey last a couple of months or even days, the experience is harsh as Bonetti mentioned and the moment they reach a European coast they are happy, pleased, and feeling safe. This is the affective investment of the traveler/migrant/refugee. He/she does not have a clue of what comes next, but he/she is pleased to be safe from the obstacles of the travel. Many times, while interviewing asylum seekers, they narrate the conditions of the journey as the most difficult part of their life is even worse than the persecution they escaped from their homeland. For young members or siblings or unaccompanied minors reaching Europe equals to be united with a family member or being themselves the means for their family to get together.

\footnotetext{
5 Three teenagers from Guatemala, Samuel, Sara and Juan decide to leave poverty and flee to the United States. Their journey is full of misfortunes, challenges but manifests in every detail their dream for the Unites States, where actually a golden cage is awaiting for them.
} 


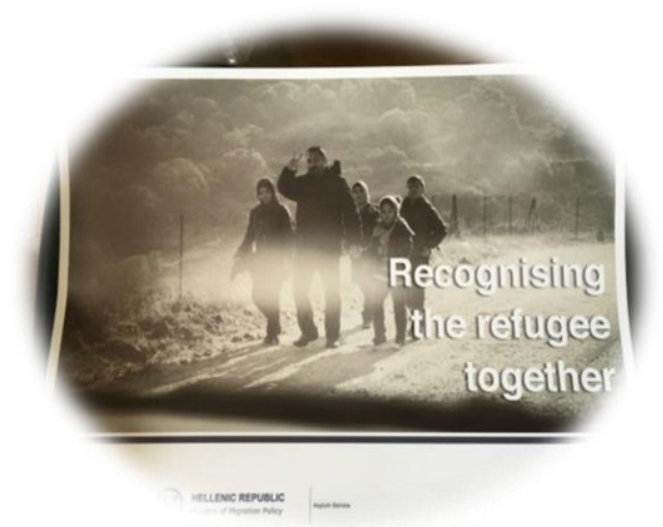

Figure 2. Bonetti's picture donated to Greek Asylum Service.

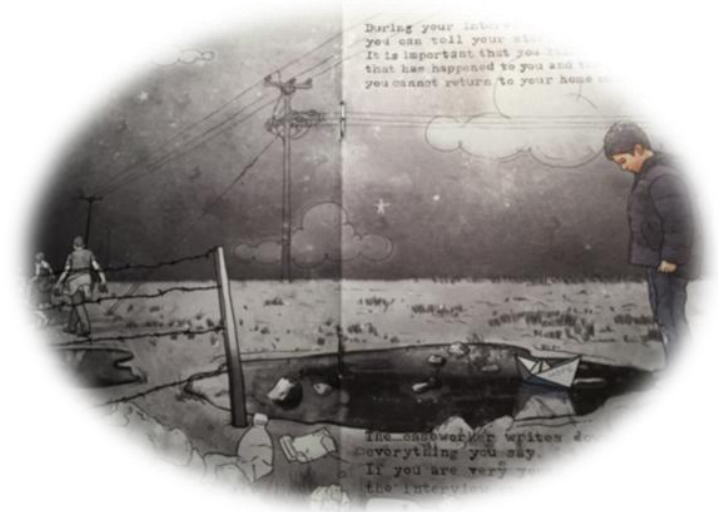

Figure 3. Leaflet of Greek Asylum Service by C.Tsevis

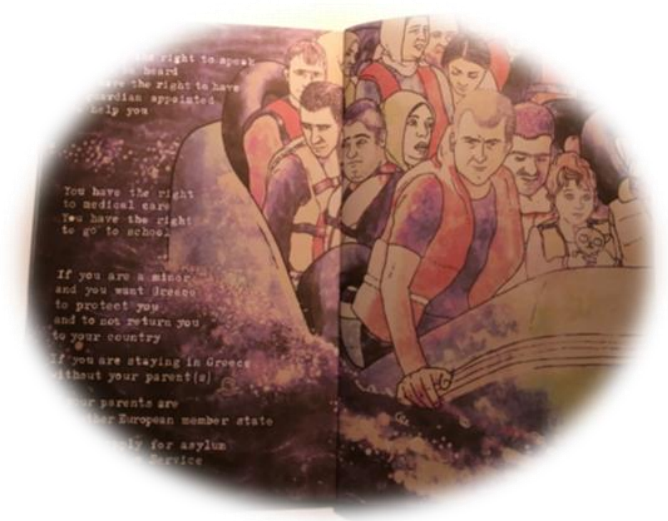

Figure 4. Leaflet of Greek Asylum Service by C.Tsevis.

Family Reunification. Family reunification is part of Dublin Convention III (604/2013), which states in art. 8-11 asylum seekers whose family members live in EU countries are eligible to the family reunification scheme. According to the official figures of the Greek Asylum Service ${ }^{6}$ from 2015-31/08-2017, 8,657 approvals by EU states have been received; 3,944 rejections and 4,170 transfers have been done. For the purpose of the scheme family members are only considered the members of nuclear family and not the extended family. Also, minor

\footnotetext{
${ }^{6}$ http://asylo.gov.gr/wp-content/uploads/2017/09/Greek-Dublin-Unit_gr.pdf [accessed 30/09/2017].
} 
members and not the adult members even if they belong to the nuclear family are accepted to the program. For instance as mentioned in the Report of Actionaid,

a Syrian woman, 53 years old, reached the island of Lesvos on 1st April 2016, she has two sons in Germany, age 24 and 21 years old, she asked for family reunification but the authorities told her that her sons are too old for that. She travelled with her niece, who decided to leave Greece illegally, so as to reach Germany ${ }^{7}$. (2017)

Hence, she could not be reunited with her sons as they are considered adults now and her mother should be left alone in another country coming out of a war zone and without her wish. Moreover, in terms of time processing the applications of family reunification, it seems that the state bureaucracy and the mechanisms applied are time consuming $^{8}$. Thus, applicants were not properly informed and had to undergo a minimum of seven months to a year or even more for being transferred safely. It should be noted that

the Special Rapporteur was informed that the Dublin procedure is often lengthy and that it may take 15 to 18 months for children to be reunited with their family members, due to DNA tests required by the receiving States. This is unacceptable and the procedure should be shortened ${ }^{9}$. (UN Human Rights Council, 2017)

This has led to many cases to the choice of illegal transfer as both child and parent could not reside to unsafe structures or for unaccompanied minors to be exploited or violated. Bonetti's picture (Figure 5) which is the first banner situated in the headquarters of the Greek Asylum Service envisions through an affective moment of father-child, the need to treat and examine applications of family members together by the member states. A strong affective moment such as this reinforces the unforeseen mistreatment migrant and refugees undergo at this particular moment. The procedure is lengthy and the adult family members are still part of the family and there applications should be considered together. Hence, if we consider that the European discourse on solidarity is based on European values and documents safeguarding human rights, then such an affective investment points out the lack of solidarity and in fact the lack of a total fullness that initiated within the margins of the family.

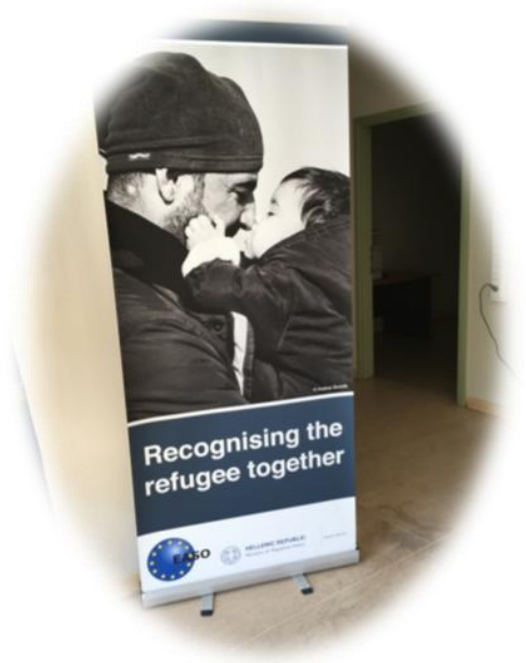

Figure 5. Bonetti's picture donated to Greek Asylum Service.

\footnotetext{
${ }^{7}$ http://www.actionaid.gr/media/1367115/Relocation_Report_AA_GR_FINAL_spreads.pdf [accessed 06/09/2017].

$8 \mathrm{http} / / /$ www.actionaid.gr/media/1367115/Relocation_Report_AA_GR_FINAL_spreads.pdf [accessed 06/09/2017].

9 UN Human Rights Council, Report of the Special Rapporteur on the Human Rights of Migrants on His Mission to Greece, 24 April 2017, A/HRC/35/25/Add.2, available at: http://www.refworld.org/docid/593a8b8e4.html [accessed 30 September 2017].
} 
Relocation Program. Last but not least, the relocation program took place in 2015 and lasted for two years following the EU Council of Europe Decision 2015/1601 [22/09/2015]. This scheme was initiated based on the principle of solidarity among EU member states, battling illegal transfer, smugglers, and unsafe conditions of movement. It aimed to the relocation of 160,000 asylum applicants. It was considered a "safe and legal way for asylum seekers to be transferred" ${ }^{10}$ from Greece and Italy to the rest of EU countries. In other words, if an applicant arrived in Greece or Italy, the relevant authorities in cooperation with the authorities of the rest of the EU countries were able to relocate the applicant, establishing a safe transfer and the new host state would process his/her application. While initially only few EU member states participated in the program, it was entered by further member states during 2016. The program referred to asylum seekers, whose country of origin had a $75 \%$ average recognition rate of international protection within the EU countries.

Bonetti's picture (Figure 6), which was taken on the very first day of relocation scheme depicts through the child's gaze the vision of a safe and legal travel bypassing the obstacles of the illegal route. The child's eyes above the plane seat affectively engage the viewer (immigrant/refugee) to a process of identification and to the promise of fantasy. The route is safe and legal.

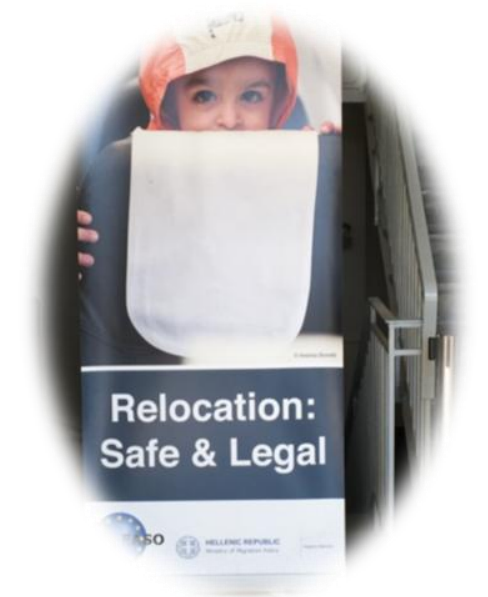

Figure 6. Bonetti's picture donated to Greek Asylum Service.

\section{Conclusion}

The paper aimed to reveal how affective investments trigger and may support the discourse of European solidarity. Having discussed the theoretical framework of solidarity and emotions we moved to the analysis of empirical data. Visual manifestations of immigrants and refugees are emotionally invested and reveal a set of issues referred directly or indirectly to European solidarity such as the migrant's travel, family reunification, and the relocation scheme. The fantasy of a European discourse, where all member states share common principles with regards to solidarity towards migrants and refugees together with the fantasy of a golden homeland, is presented in the pictures.

Affectively investing the identity of refugee and migrant succeeds in constantly posing the question of solidarity. Emotions reflect the culture of a particular social group and form ontologically parts of a human identity. Without emotion humans are empty and the gap between jouissance and fantasy is stressed. This journey in terms of solidarity can be bridged by cultural empathy.

${ }^{10} \mathrm{https}: / / \mathrm{www}$. easo.europa.eu/about-relocation [accessed 12/09/2017]. 
Looking at both projects, Bonetti's photos and Tsevis graphic designing, it is clear that the aim is identification and cultural empathy through affect. Colors, faces, gazes, and postures signify the world of difference and the discussion between insiders/outsiders. Minors are fragile and different but have rights and need a brighter future from the one they escaped from. European treaties and documents referring to Child Protection, family unity, are prolific, but their implementation is not a fact but a question in practice. Children's trafficking, smuggling, exploitation, violence, and racism are more of a routine. European solidarity discourse should tackle these issues. Affect is a vehicle to empathy and, thus, to fantasy.

\section{References}

Acropolis Museum. (2017). Exhibition brochure, emotions a world of emotions.

Benvenuto, B\&Kennedy, R., (1986) The works of Jacques Lacan, London: Association Books.

Fernandes, S., \& Rubio E. (2012). Solidarity within the Eurozone: How Much, What For, For How Long? Report, No. 51, Notre

Europe. $\quad$ Retrieved November $\quad 9, \quad$ 2013, from

http://www.notre-europe.eu/uploads/tx_publication/SolidarityEMU_S.Fernandes-E.Rubio_NE_Feb2012.pdf

Freeden M. (1996). Ideologies and Political Theory. A Conceptual Approach. Oxford: University Press.

Glynos, J., \& Stavrakakis, Y. (2008). Lacan and political subjectivity: Fantasy and enjoyment in psychoanalysis and political theory. Paper presented at the 58th PSA Annual Conference Swansea, 1-3 April 2008.

Glynos, J. (2011). On the ideological and political significance of fantasy in the organization of work. Psychoanalysis, Culture \& Society, 16(4), 373-393.

Glynos, J., \& Mondon, A. (2016). The political logic of populist hype: The case of right-wing populism's "meteoric rise" and its relation to the status quo. Populismus Working Papers, No. 4.

Harding, J., \& Pribram, E. D. (2009). Emotions: A cultural studies reader. London: Routledge.

Hawkins, B. (2015). Fantasies of subjugation: A discourse theoretical account of British policy on the European Union. Critical Policy Studies, 9(2), 139-157. doi:10.1080/19460171.2014.951666

Kontochristou, M. \& Mascha, E. (2014). The Euro Crisis and the question of solidarity in the European Union: Disclosures and manifestations in the European Press. Review of European Studies, Vol. 6, No. 2.

Marttila, T. (2015). Post-foundational discourse analysis: From political difference to empirical research. London: Palgrave.

Marttila, T. (Ed.). (2018). Discourse, culture and organization: Inquiries into relational structures of power. London: Palgrave Macmillan.

Pribram, E. D., \& Harding, J. (2004). Losing our cool? Following Williams and Grossberg on emotions. Faculty Works: Communications. Cultural Studies, 18(6), 863-883. Retrieved from http://digitalcommons.molloy.edu/com_fac/9

Ruitenberg, C. (2010). Conflict, affect and the political: On disagreement as democratic capacity. Journal of Peace, Education and Social Justice, 4(1), 40-55.

Stavrakakis, Y. (2005). Passions of identification: Discourse, enjoyment, and European identity. In D. Howarth and J. Torfing (Eds.), Discourse theory in European politics (pp. 68-92). London: Palgrave Macmillan.

Stavrakakis, Y. (2012). H $\lambda \alpha \kappa \alpha \nu \imath \kappa \eta ́ ~ \alpha \rho \imath \sigma \tau \rho \alpha \dot{~(=~ T h e ~ L a c a n i a n ~ l e f t: ~ P s y c h o a n a l y s i s, ~ t h e o r y, ~ p o l i t i c s) . ~(A . ~ K i o u p k i o l i s, ~ T r a n s .) . ~}$ Athens: Savalas.

Sternberg, R. J. (2002). Smart people are not stupid, but they sure can be foolish: The imbalance theory of foolishness. In R. J. Sternberg (Ed.), Why smart people can be so stupid (pp. 232-242). New Haven, USA: Yale University Press.

Skinner, A. (1980). The Foundations of Modern Political Thought (Vols. I-III). Cambridge: Cambridge University Press.

Stjernø, S. (2005). Solidarity in Europe: The History of an Idea. Cambridge: Cambridge University Press. http://dx.doi.org/10.1017/CBO9780511490378

Vignon, J. (2011). Solidarity and Responsibility in the European Union. Notre Europe Policy Brief, No. 26, June 2011. Retrieved November 9, 2013, from http://www.notre-europe.eu/uploads/tx_publication/Bref27_JVignon_EN.pdf

Zizek, S. (1989). The sublime object of ideology. London: Verso. 